\title{
Stability-Indicating Photochemical Method for the Assay of Riboflavin: Lumichrome Method
}

\author{
Iqbal Ahmad, Syed Haider Abbas, Zubair Anwar, Muhammad Ali Sheraz, \\ Sofia Ahmed, Adeel Arsalan, and Raheela Bano
}

Baqai Institute of Pharmaceutical Sciences, Baqai Medical University, Toll Plaza, Super Highway, Gadap Road, Karachi 74600, Pakistan

Correspondence should be addressed to Muhammad Ali Sheraz; ali_sheraz80@hotmail.com

Received 10 December 2014; Accepted 3 February 2015

Academic Editor: Henryk Kozlowski

Copyright (C) 2015 Iqbal Ahmad et al. This is an open access article distributed under the Creative Commons Attribution License, which permits unrestricted use, distribution, and reproduction in any medium, provided the original work is properly cited.

\begin{abstract}
A stability-indicating photochemical method for the assay of riboflavin (RF) in photodegraded samples and aged vitamin preparations has been developed. It is based on photochemical conversion of RF to lumichrome (LC) in alkaline solution under controlled conditions of light intensity, temperature, $\mathrm{pH}$, time of exposure, and distance. Under these conditions about two-thirds of RF is converted to LC and on the basis of the RF: LC ratio the concentration of RF can be determined in degraded solutions. The method involves the extraction of photolyzed solutions of RF ( $\mathrm{pH}$ 2.0) with chloroform and determination of LC along with lumiflavin (LF) by a two-component spectrometric method at 356 and $445 \mathrm{~nm}$. The method has been validated and the results of the assay of RF in photodegraded solutions compare well with those of the standard USP fluorimetric method. The recovery of the method is $99-101 \%$ and the precision is within $2 \%$. The method is stability-indicating and can be applied to the assay of RF in photodegraded solutions and aged vitamin preparations. The method is specific compared to that of the USP fluorimetric method in which the degraded LC may interfere with the fluorescence emission of RF.
\end{abstract}

\section{Introduction}

Riboflavin (RF) is sensitive to light in aqueous solution [1-3]. It is photodegraded by several pathways involving the excited singlet and excited triplet states [4-10]. These reactions lead to the formation of several photoproducts under various conditions $[6,11-18]$. The primary step in the photodegradation of RF solutions involves the formation of formylmethylflavin (FMF) by photoreduction. This compound then undergoes hydrolytic degradation to form lumichrome (LC) and lumiflavin (LF) as the final products [12, 14-18]. Spectrometric methods have been used to assay RF in pharmaceutical preparations [2] and in photodegraded solutions in 440$450 \mathrm{~nm}$ region [12, 19-26]. In view of the interference of photoproducts of RF absorbing at the analytical wavelength, the accuracy of these methods is doubtful and the results may not be reliable. The development of multicomponent spectrometric methods involving the assay of RF and its major photoproducts in degraded solutions $[14,15,27]$ leads to the study of the kinetics of photodegradation reactions [14-18, 28]. Warburg and Christian [11] made an attempt to assay RF involving the photochemical formation of LF by its side-chain cleavage in alkaline solution, its extraction in chloroform, and measurement of absorbance at $450 \mathrm{~nm}$. However, the nonquantitative nature of the reaction limited the use of this method. The principle of photochemical oxidation of thiamine (vitamin $B_{1}$ ) to thiochrome followed by fluorescence measurement has also been applied to the assay of thiamine $[29,30]$. In the present study a stability-indicating photochemical method has been developed for the assay of $\mathrm{RF}$ on the basis of the formation of LC, a major reaction product, under controlled conditions of light, temperature, $\mathrm{pH}$, irradiation source-vessel distance, and irradiation time. The method has been validated under controlled experimental conditions and could be applied to the assay of RF in photodegraded solutions and aged vitamin preparations. 


\section{Experimental}

2.1. Materials. RF, LC, and LF were purchased from Sigma Chemical Co. FMF was synthesized according to the method of Fall and Petering [31]. All other reagents and solvents were of analytical grade or of the purest form available from Merck \& Co. Commercial vitamin preparations of different pharmaceutical concerns were obtained from the market. The following buffer systems were used: $\mathrm{KH}_{2} \mathrm{PO}_{4}-\mathrm{Na}_{2} \mathrm{HPO}_{4}$, pH 7.0-8.0, $\mathrm{Na}_{2} \mathrm{~B}_{4} \mathrm{O}_{7}-\mathrm{HCl}, \mathrm{pH}$ 8.5-9.0, $\mathrm{Na}_{2} \mathrm{~B}_{4} \mathrm{O}_{7}-\mathrm{NaOH}, \mathrm{pH}$ 9.5-10.5, and $\mathrm{Na}_{2} \mathrm{HPO}_{4}-\mathrm{NaOH}, \mathrm{pH}$ 11.6. The ionic strength was $0.005 \mathrm{M}$ in each case.

2.2. Photolysis. A $5 \times 10^{-5} \mathrm{M}(18.82 \mathrm{mg} / \mathrm{L})$ aqueous solution of $\mathrm{RF}$ was prepared in the $\mathrm{pH}$ range $7.0-11.6$ in a $100 \mathrm{~mL}$ Pyrex flask and placed in a thermostat water bath at $25 \pm 0.1^{\circ} \mathrm{C}$. The solution was irradiated using a Philips HPL-N $125 \mathrm{~W}$ high pressure mercury vapor lamp (emission at 405 and $435 \mathrm{~nm}$, the long wavelength corresponding to the absorption maximum, $445 \mathrm{~nm}$ of RF) [7, 10, 16-18], fixed horizontally at a distance of $25 \mathrm{~cm}$ from the centre of the vessel in a radiation chamber. The solution was continuously bubbled with a stream of air into the flask to maintain aerobic conditions. Samples were withdrawn at the appropriate intervals for chromatographic examinations and spectrometric assay.

2.3. Thin-Layer Chromatography (TLC). The identification of RF and its photoproducts, FMF, LC, and LF, has been carried out by performing TLC of the irradiated solutions using $250 \mu \mathrm{m}$ cellulose plates and solvent systems: (a) 1-butanolacetic acid-water $(40: 10: 50, \mathrm{v} / \mathrm{v}$, organic phase) and (b) 1butanol-1-propanol-acetic acid-water $(50: 30: 2: 18, \mathrm{v} / \mathrm{v})[28]$. The compounds were detected by comparison of their $R_{f}$ values and fluorescence emission under $365 \mathrm{~nm}$ (RF, LF, and FMF, yellow green; LC, sky blue) with those of the reference standards.

2.4. $\mathrm{pH}$ Measurement. The measurement of the $\mathrm{pH}$ of solutions was performed on an Elmetron LCD display $\mathrm{pH}$ meter (Model-CP 501, sensitivity $\pm 0.01 \mathrm{pH}$ units, Poland) using a combination $\mathrm{pH}$ electrode. The electrode was automatically calibrated using phthalate ( $\mathrm{pH} 4.008)$, phosphate ( $\mathrm{pH} 6.865)$, and disodium tetraborate ( $\mathrm{pH} 9.180)$ buffer solutions.

2.5. Spectral Determination. The spectral determinations on photodegraded solutions of RF were carried out on a Shimadzu UV-1601 spectrophotometer using quartz cells of $10 \mathrm{~mm}$ path length.

2.6. Light Intensity Determination. The intensity of the Philips HPL-N $125 \mathrm{~W}$ lamp has been determined using potassium ferrioxalate actinometry by the method of Hatchard and Parker [32] and a value of $1.20 \pm 0.10 \times 10^{17}$ quanta s $^{-1}$ has been obtained.

2.7. Spectrometric Assay of RF and Photoproducts. The assay of RF and its photoproducts (FMF, LC, and LF) for the degradation reactions at $\mathrm{pH}$ of $7.0-11.6$ has been carried out by the multicomponent spectrometric method of Ahmad and Rapson [14]. It involves the adjustment of the $\mathrm{pH}$ of photodegraded solutions of RF to $\mathrm{pH} 2.0$ with $0.2 \mathrm{M} \mathrm{HCl}-$ $\mathrm{KCl}$ buffer, extraction of the solution with $3 \times 10 \mathrm{~mL}$ chloroform to remove LC and LF, and evaporation of chloroform and dissolution of the residue in $0.2 \mathrm{M}$ acetate buffer $(\mathrm{pH}$ 4.5). The absorbance of the solution was measured at 356 and $445 \mathrm{~nm}$ and the concentrations of LC along with LF were determined by a two-component spectrometric assay [33]. The absorbance of the aqueous layer ( $\mathrm{pH} 2.0)$ was measured at 385 and $445 \mathrm{~nm}$ to determine the concentrations of RF and FMF by a two-component spectrometric assay. The protonated form of FMF $\left(p K_{a} 3.5\right)$ [34] at $\mathrm{pH} 2.0$ has as an absorption maximum $(385 \mathrm{~nm})$ distinct from that of RF $(445 \mathrm{~nm})$ to make the two-component assay feasible.

2.8. Photochemical Assay of RF. An aliquot of the photodegraded solution (1-2 mL, corresponding to about $1 \times 10^{-4} \mathrm{M}$ $\mathrm{RF}$ ) was placed in a $25 \mathrm{~mL}$ beaker, $5 \mathrm{~mL}$ of water was added, and the $\mathrm{pH}$ was adjusted to 2.0 with $1 \mathrm{M} \mathrm{HCl}$ solution. The solution was transferred to a $10 \mathrm{~mL}$ volumetric flask and made up to volume with $\mathrm{KCl}-\mathrm{HCl}$ buffer solution. The solution was extracted with $3 \times 10 \mathrm{~mL}$ of chloroform to remove the degradation products and the chloroform layer was discarded. A $5 \mathrm{~mL}$ quantity of the aqueous phase was placed in a $25 \mathrm{~mL}$ beaker and the $\mathrm{pH}$ adjusted to 11.6 with $2 \mathrm{M} \mathrm{NaOH}$ solution. The solution was transferred to a $10 \mathrm{~mL}$ volumetric flask and made up to volume with $\mathrm{pH} 11.6 \mathrm{Na}_{2} \mathrm{HPO}_{4}-\mathrm{NaOH}$ buffer solution. This solution was then subjected to photolysis as described under Section 2.2. The concentration of LC along with LF was determined on complete photolysis of RF and FMF in the solutions by two-component spectrometric assay at 356 and $445 \mathrm{~nm}$.

2.9. Fluorescence Measurements. The fluorescence measurements on RF solutions were carried out at room temperature $\left(\sim 25^{\circ} \mathrm{C}\right)$ with a Spectromax 5 fluorimeter (Molecular Devices, Sunnyvale, CA, USA) in the end point mode using $374 \mathrm{~nm}$ as the excitation wavelength and $530 \mathrm{~nm}$ as the fluorescence emission wavelength $[35,36]$. The fluorescence was measured in relative fluorescence units using a pure $0.05 \mathrm{mM} \mathrm{RF}$ solution as standard.

\section{Results and Discussion}

3.1. Identification of Photoproducts of RF. In a degradation study, it is necessary to identify the products formed in the reaction to develop a stability-indicating analytical method for the assay of one or more compounds. A TLC study of the photodegraded solution of RF during irradiation using solvent systems (a) and (b) confirmed the presence of FMF, LC, and LF as the main photoproducts in addition to undegraded RF. A minor spot of carboxymethylflavin (CMF) has also been detected which is reported to be formed within $1 \%$ of the photodegraded solution [18].

3.2. Assay of RF. The assay of RF has been performed on the basis of the separation of photoproducts by chloroform 
TABLE 1: Validation data for multicomponent spectrometric assay of RF, LC, and $\mathrm{LF}^{\mathrm{a}}$.

\begin{tabular}{lccc}
\hline Compound & RF & LC & LF \\
\hline$\lambda_{\text {max }}$ nm (pH 2.0) & 445 & 356 & 445 \\
Molar absorptivity $(\epsilon) \mathrm{M}^{-1} \mathrm{~cm}^{-1}$ & 12500 & 10800 & 10400 \\
Linearity & & & $0.5-5.0 \times 10^{-5}$ \\
$\quad$ Concentration range (M) & $0.5-5.0 \times 10^{-5}$ & 1.080 & $0.5-5.0 \times 10^{-5}$ \\
Slope $\times 10^{-4}$ & 1.250 & 0.0044 & 1.040 \\
Intercept & 0.0026 & \pm 0.003 & 0.0035 \\
SD of slope & \pm 0.003 & 1.415 & \pm 0.005 \\
SE of slope & 0.968 & $98.2-100.6$ & 1.025 \\
Recovery range (\%) & $98.5-101.2$ & $99.8 \pm 1.58$ & $98.0-101.8$ \\
Accuracy (\%) \pm SD & $100.2 \pm 1.21$ & 1.50 & $99.7 \pm 1.50$ \\
RSD (\%) & 1.20 & $1.251 \times 10^{-6}$ & 1.59 \\
LOD (M) & $1.195 \times 10^{-6}$ & $4.405 \times 10^{-6}$ & $2.160 \times 10^{-6}$ \\
LOQ (M) & $4.183 \times 10^{-6}$ & & $4.420 \times 10^{-6}$ \\
\hline
\end{tabular}

${ }^{\mathrm{a}}$ Values are mean of five determinations.

TABLE 2: Concentrations of RF and photoproducts at $\mathrm{pH}$ 11.6.

\begin{tabular}{lccccc}
\hline Time $(\mathrm{min})$ & $\mathrm{RF}\left(\mathrm{M} \times 10^{-5}\right)$ & $\mathrm{FMF}\left(\mathrm{M} \times 10^{-5}\right)$ & $\mathrm{LC}\left(\mathrm{M} \times 10^{-5}\right)$ & $\mathrm{LF}\left(\mathrm{M} \times 10^{-5}\right)$ & 0.00 \\
\hline 0 & 5.00 & 0.00 & 0.00 & 0.56 & Total $\left(\mathrm{M} \times 10^{-5}\right)^{\mathrm{a}}$ \\
6 & 3.32 & 0.41 & 0.65 & 0.94 & 4.00 \\
12 & 1.96 & 0.68 & 1.37 & 1.36 & 4.95 \\
18 & 1.02 & 0.62 & 1.93 & 1.61 & 4.93 \\
24 & 0.48 & 0.47 & 2.36 & 1.81 & 4.92 \\
30 & 0.26 & 0.18 & 2.67 & 2.06 & 4.92 \\
36 & 0.00 & 0.00 & 2.89 & 4.95 \\
\hline
\end{tabular}

${ }^{a} \mathrm{~A}$ little loss in molar balance is due to the formation of minor photoproducts such as CMF and others which have not been accounted for in the assay.

extraction [14]. In order to set the conditions for photochemical conversion of RF to LC, the assay of RF and photoproducts (including LC) has been carried out at various irradiation intervals to determine optimal conditions for the method. The photodegradation reactions have been carried out in the $\mathrm{pH}$ range $7.0-11.6$ to determine the $\mathrm{pH}$ at which maximum amount of LC is formed on complete disappearance of RF and FMF. The method requires strict control of conditions to achieve reproducible results. The various analytical parameters for the validation of this method are reported in Table 1.

3.2.1. RF and Photoproduct Ratios. The results of a complete assay of $\mathrm{RF}$ and photoproducts at $\mathrm{pH} 11.6$ (maximum LC yield) are reported in Table 2. A constant molar balance at various time intervals with respect to the initial concentration of RF is an indication of the accuracy and precision of the method. The values of the ratios of FMF/RF and LC/LF and the percentage of LC and LF formed at complete disappearance of RF and FMF $(\mathrm{FMF} / \mathrm{RF}=0)$ at $\mathrm{pH}$ of $7.0-11.6$ are reported in Table 3. In this assay it is necessary to optimize the experimental conditions to achieve maximum yield of LC in relation to RF within a reasonable period of irradiation time. These ratios indicate that the maximum yield of LC for a photodegradation reaction of $\mathrm{RF}$ is obtained at $\mathrm{pH}$ around
11.0 ( $36 \mathrm{~min}$ ). However, the complete disappearance of RF and FMF takes place at $\mathrm{pH} 11.6$ in a period of about $30 \mathrm{~min}$. Therefore, this $\mathrm{pH}$ is considered as the optimum $\mathrm{pH}$ for the photodegradation reaction of RF for the assay purpose. Under the present conditions with the lamp used in the study, $30 \mathrm{~min}$ is considered enough to achieve the maximum yield of LC. The assay data showed that the concentration of LC is gradually increasing, with time, until becoming almost constant ( $\sim 60 \%$ conversion of RF concentration) towards the end of the reaction on complete disappearance of $\mathrm{RF}$ and FMF. A plot of LC/LF versus $\mathrm{pH}$ is shown in Figure 1 to indicate that a constant ratio is obtained on complete disappearance of RF and FMF. On the other hand, at this $\mathrm{pH}$ the concentration of LF is decreasing, with time, indicating the cleavage of isoalloxazine nucleus in the alkaline solution [37-39]. The LC/LF ratio at $\mathrm{pH} 11.6$ at $30 \mathrm{~min}$ is around 1.30 . A plot of \% concentrations of LC and LF formed at different $\mathrm{pH}$ values shows the maximum concentration at $\mathrm{pH} 11.6$ (Figure 2). The earlier photochemical method for the assay of RF, based on the formation of LF in alkaline medium [11], does not give accurate results due to the lack of control of experimental conditions and the loss of LF by isoalloxazine ring cleavage. Moreover, LF concentrations at $\mathrm{pH} 11.6$ are lower than those of LC on the basis of LC/LF ratios. 
TABLE 3: Molar ratios of RF $\left(5 \times 10^{-5}\right)$ and photoproducts at $\mathrm{pH}$ of 7.0-11.6.

\begin{tabular}{|c|c|c|c|c|c|}
\hline $\mathrm{pH}$ & Time $(\min )$ & FMF/RF ${ }^{\mathrm{a}}$ & LC/LF & \% LC formed ${ }^{b, c}$ & \% LF formed \\
\hline \multirow{2}{*}{7.0} & 180 & 00 & 2.48 & 20 & 08 \\
\hline & 30 & 0.62 & 3.63 & 13 & 08 \\
\hline \multirow{2}{*}{8.0} & 160 & 00 & 3.66 & 29 & 18 \\
\hline & 30 & 0.36 & 3.60 & 24 & 16 \\
\hline \multirow{2}{*}{9.0} & 110 & 00 & 5.31 & 40 & 25 \\
\hline & 30 & 0.16 & 4.88 & 34 & 22 \\
\hline \multirow{2}{*}{10.0} & 48 & 00 & 1.49 & 49 & 30 \\
\hline & 30 & 0.07 & 1.46 & 44 & 30 \\
\hline \multirow{2}{*}{11.0} & 36 & 00 & 2.21 & 57 & 46 \\
\hline & 30 & 4.88 & 2.20 & 56 & 37 \\
\hline \multirow{2}{*}{$11.6^{\mathrm{d}}$} & 36 & 00 & 1.40 & 58 & 41 \\
\hline & 30 & 0.69 & 1.48 & 53 & 36 \\
\hline
\end{tabular}

${ }^{a}$ The complete photolysis of RF and FMF as confirmed by disappearance of spots in TLC studies.

${ }^{\mathrm{b}} \mathrm{LC}$ : RF ratio $0.58: 1.0$, conversion factor 1.724 .

${ }^{\mathrm{c}} \mathrm{LC}$ concentration $($ Table 2$)=2.89 \times 10^{-5} \mathrm{M}$.

${ }^{\mathrm{d}} \mathrm{RF}$ concentration $=2.89 \times 10^{-5} \times 1.724=4.98 \times 10^{-5} \mathrm{M}=1.876 \mathrm{mg} / 100 \mathrm{~mL}$.

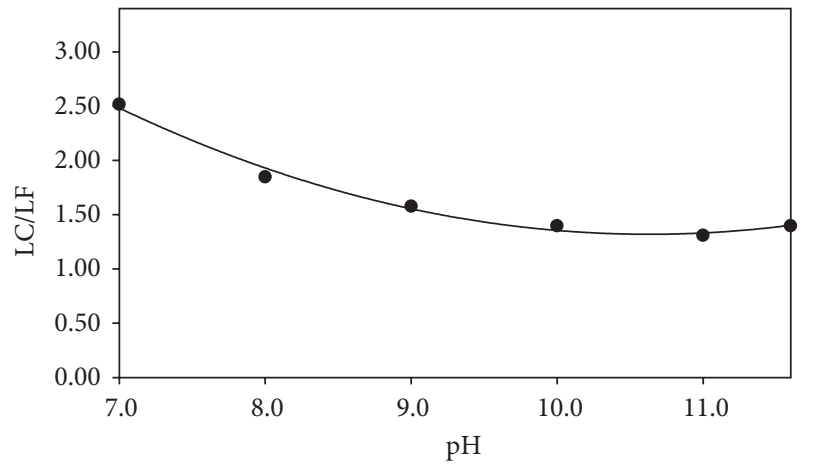

FIGURE 1: A plot of LC/LF ratio versus $\mathrm{pH}$ on complete disappearance of RF.

Thus the determination of LC would give better results for the assay of RF compared to that of LF and would be stabilityindicating. The experimental conditions for the method have to be established by the analyst to determine the LC : RF ratio.

\subsubsection{Analytical Parameters}

(1) Choice of Analytical Wavelengths. The photodegraded solutions of RF were subjected to chloroform extraction for the separation of two components (LC and LF). These components have been determined by a two-component spectrometric assay at 356 and $445 \mathrm{~nm}$. These wavelengths belong to the absorption maxima of these compounds and are most suitable for their assay by a spectrometric method [14]. These wavelengths would also provide maximum sensitivity and specificity to the assay method. In the present method, the assay of LC is required only for the determination of RF using the LC: RF ratio.

(2) Choice of Assay $p H$. According to the original assay method of Ahmad and Rapson [14], a pH of 2.0 gives

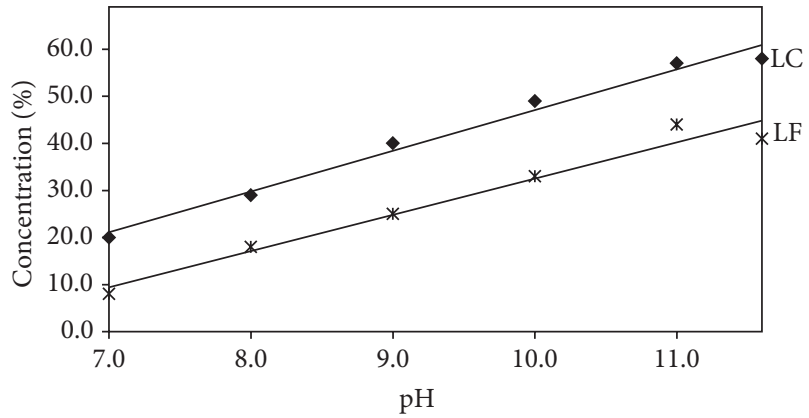

Figure 2: A plot of $\%$ concentration of LC $(\diamond)$ and LF $(*)$ formed versus $\mathrm{pH}$.

maximum distinction between the absorption maxima of FMF $(385 \mathrm{~nm})$ and RF $(445 \mathrm{~nm})$. At this $\mathrm{pH}$ FMF is protonated $\left(p K_{a} 3.5\right)$ [34] and remains in the aqueous phase. Moreover, FMF is unstable at pH 7.0 and above and does not interfere with the assay of LC and LF as it is not extracted in chloroform [14]. LC and LF, on chloroform extraction, can be conveniently assayed at 356 and $445 \mathrm{~nm}$ since they exhibit considerable difference in their absorption maxima at that $\mathrm{pH}$. The photodegradation reactions of RF carried out at any $\mathrm{pH}$ are subjected to this treatment by adjusting the $\mathrm{pH}$ of degraded solutions to $\mathrm{pH} 2.0$ before chloroform extraction.

(3) Beer's Law Relation. The validity of Beer's law for RF and its photoproducts, individually and in mixtures, has been confirmed in the concentration range employed for assay $\left(1-5 \times 10^{-5} \mathrm{M}\right)$ at various analytical wavelengths. The molar absorptivities used in the calculations of concentrations of RF, FMF, LC, and LF have previously been reported [14] and have been used in several photodegradation studies of RF [14-18]. The values of molar absorptivities determined in this study are reported in Table 1 . In the photochemical assay of RF, 
<smiles>Cc1cc2nc3c(=O)[nH]c(=O)nc-3n(C[C@H](O)[C@H](O)[C@H](O)CO)c2cc1C</smiles>

LC<smiles>Cc1cc2nc3c(=O)[nH]c(=O)nc-3n(CC=O)c2cc1C</smiles>

FMF

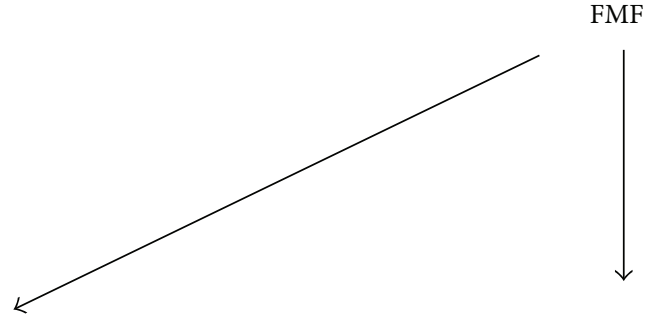<smiles>Cc1cc2nc3c(=O)[nH]c(=O)nc-3n(C)c2cc1C</smiles>

LF

FIGURE 3: Scheme for the photodegradation of RF in alkaline solution.

the concentration of LC is calculated in the range where Beer's law relation holds.

(4) Precision of the Method. The precision of the method has been determined by the analysis of synthetic mixtures of RF and its photoproducts, LC and LF, and the value of RSD has been found to be within $\pm 2 \%$ (Table 1 ).

\subsubsection{Experimental Conditions}

(1) Radiation Source. A medium intensity radiation source is suitable for the photodegradation of RF. Under the experimental conditions used the irradiation source should degrade $\mathrm{RF}$ uniformly in the alkaline media by a fixed mechanism in a reasonable period of time and avoid any side reactions affecting the formation of LC. In the present study a Philips HPL-N $125 \mathrm{~W}$ high pressure mercury vapor fluorescent lamp, emitting in the region of RF absorption ( $445 \mathrm{~nm}$ ), has been found to be suitable for the photodegradation studies of RF. It has previously been used in several photodegradation studies of RF [15-18, 28].

(2) Radiation Vessel. A radiation vessel of standard brand should be used in the photodegradation of RF. The vessel should have uniform wall thickness and be always placed in the same orientation. A Pyrex flask $(100 \mathrm{~mL})$ could be used for these studies since the light absorption in the solution should be uniform throughout irradiation. Such flasks have successfully been used in earlier studies on the photodegradation of RF [15-18].

(3) Radiation Source-Vessel Distance. This distance is critical since change in this distance in photodegradation work would give nonuniform assay results. It is, therefore, necessary to fix this distance during exposure. A distance of $\sim 25 \mathrm{~cm}$ between the radiation source and the reaction vessel has also been found suitable for this work and has also been used in previous studies [15-18].

(4) Temperature. A change in the temperature of RF solutions during irradiation may introduce thermal effects causing changes in the nature and rate of the photodegradation reaction. The irradiation should be carried out in a thermostat water bath at $25 \pm 1^{\circ} \mathrm{C}$ to avoid the effect of any change in temperature during an experiment.

(5) Irradiation Time. The time required for irradiation of RF solutions would depend on the formation of maximum amount of LC on complete disappearance of RF and FMF in the photodegradation reaction. In the present case a time 
TABLE 4: Assay of RF in photodegraded samples and aged vitamin preparations $\left(25 \pm 1^{\circ} \mathrm{C}\right)$.

\begin{tabular}{|c|c|c|c|c|c|c|c|c|}
\hline \multirow[b]{2}{*}{ Method } & \multicolumn{4}{|c|}{ Sample stored in transparent containers $(\mathrm{pH} 7.0)^{\mathrm{a}}$} & \multicolumn{4}{|c|}{ Vitamin preparations stored in original package $(\mathrm{pH} 3-4)^{b}$} \\
\hline & $\begin{array}{c}\text { Added } \\
(\mathrm{mg} / 100 \mathrm{~mL})\end{array}$ & $\begin{array}{c}\text { Found } \\
(\mathrm{mg} / 100 \mathrm{~mL})\end{array}$ & $\%$ recovery & $\%$ RSD & $\begin{array}{c}\text { Labeled } \\
(\mathrm{mg} / 100 \mathrm{~mL})\end{array}$ & $\begin{array}{c}\text { Found } \\
(\mathrm{mg} / 100 \mathrm{~mL})\end{array}$ & $\%$ recovery & $\%$ RSD \\
\hline \multicolumn{9}{|l|}{$\begin{array}{l}\text { USP } \\
\text { fluorimetric } \\
\text { method }^{c}\end{array}$} \\
\hline Sample 1 & 33.2 & 21.46 & 64.63 & 1.39 & 33.2 & 30.31 & 91.29 & 1.33 \\
\hline Sample 2 & 24.0 & 15.16 & 63.16 & 1.97 & 24.0 & 22.40 & 93.33 & 1.75 \\
\hline Sample 3 & 50.0 & 35.42 & 70.84 & 1.55 & 50.0 & 44.75 & 89.50 & 1.45 \\
\hline \multicolumn{9}{|l|}{ LC method ${ }^{c}$} \\
\hline Sample 1 & 33.2 & 20.88 & 62.89 & 1.97 & 33.2 & 29.63 & 89.24 & 1.98 \\
\hline Sample 2 & 24.0 & 14.80 & 61.66 & 1.97 & 24.0 & 22.30 & 92.91 & 1.81 \\
\hline Sample 3 & 50.0 & 35.31 & 70.62 & 1.96 & 50.0 & 43.99 & 87.98 & 1.88 \\
\hline
\end{tabular}

${ }^{\mathrm{a}}$ Light for $4 \mathrm{~h}$.

${ }^{\mathrm{b}}$ Room light for 6 months.

${ }^{\mathrm{c}}$ The tabulated $t$ value at the $95 \%$ confidence level for five degrees of freedom is 2.571 and the calculated $t$ value is 1.950 . Therefore, $t_{\text {calc }}<t_{\text {table }}$ and there is no significant difference between the two methods at this confidence level.

period of about $30 \mathrm{~min}$ has been found to be sufficient to achieve the maximum amount of LC for the reaction carried out at $\mathrm{pH}$ 11.6.

(6) Air Content. A constant air content in RF solutions subjected to irradiation is necessary to create aerobic conditions for the reaction to achieve a uniform output of LC on the photodegradation of RF. A steady bubbling of a stream of air into the irradiation flask would produce an aerobic atmosphere for the reaction to achieve the desired concentration of LC.

3.2.4. Photodegradation of RF in Alkaline Solution. It is well known that aqueous RF solutions undergo photodegradation by intramolecular photoreduction of the isoalloxazine nucleus involving the ribityl side chain [4-10]. This leads to the formation of FMF as an intermediate product in both acid and alkaline solutions [12-18]. FMF forms LC in acid solution by a bimolecular mechanism and LC and LF in alkaline solutions by a unimolecular mechanism $[14,15,18$, 28]. The concentration of LC is greater than LF up to $\mathrm{pH}$ 11.6. In the $\mathrm{pH}$ range above 9.0, isoalloxazine nucleus of flavins is gradually cleaved to form products absorbing in the UV region [13]. This may cause some interference in the assay of LF present in photodegraded solutions. A reaction scheme for the photodegradation of RF in alkaline solution is presented in Figure 3. A plot of RF and products during the photodegradation reaction at $\mathrm{pH} 11.6$ is shown in Figure 4.

3.3. Application of the Assay Method. The LC method can be applied to the assay of RF in photodegraded solution and in aged vitamin preparations. It is stability-indicating in the determination of RF concentrations on the basis of the amount of LC formed under controlled conditions.

In the application of this method to degraded solution and aged vitamin preparations, it is necessary to extract any LC formed prior to the photolysis of RF according to the

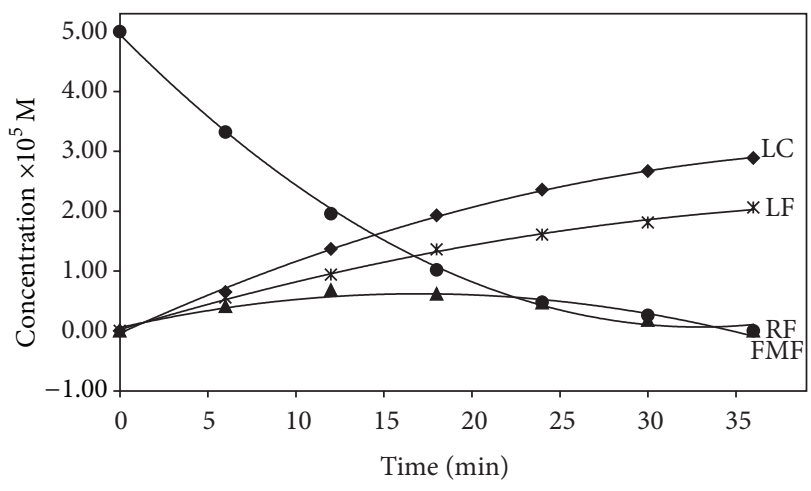

FIGURE 4: A plot of concentration versus time for the photodegradation of RF and its photoproducts at $\mathrm{pH}$ 11.6.

method described under Section 2.8. This would differentiate between the LC already present as a degradation product and the LC formed on the photolysis of RF. The latter would give an estimate of the amount of RF present in degraded samples.

A comparison of the results of the LC method with those of a standard USP fluorimetric method [36] for the assay of RF in photodegraded solutions and in aged vitamin preparations is given in Table 4. The values of the assay obtained by LC method are slightly lower than those of the fluorimetric method indicating that the LC method can be used to obtain reliable results for the assay of RF in degraded samples. There is statistically no significant difference between the result of the proposed LC method and the standard USP fluorimetric method, as indicated by the $t$-test (Table 4 ).

The advantage of the LC method is that it determines RF purely on the basis of its concentration actually present in degraded samples. On the contrary the fluorimetric method may have some interference due to the presence of LC $\left(\lambda_{\text {fluor }}\right.$ $485 \mathrm{~nm}$ ) [40] as indicated by slightly higher values of the assay of RF compared to those obtained by LC method. 


\section{Conclusion}

RF is extensively used as a component of vitamin preparations. It is sensitive to light and undergoes degradation in aqueous solution to form a number of photoproducts. A photochemical stability-indicating assay method has been developed for the determination of RF in photodegraded solutions and in aged vitamin preparations. The method involves photochemical conversion of RF to LC at $\mathrm{pH} 11.6$ on exposure to light and its determination by chloroform extraction under controlled experimental conditions. It can be used for the determination of RF using the values of the ratios of concentration of LC formed to that of the initial concentration of RF used in assay (LC: RF). The method has good accuracy and precision. It has specific application for the determination of RF in photodegraded solutions and in aged vitamin preparations.

\section{Conflict of Interests}

The authors declare that there is no conflict of interests regarding the publication of this paper.

\section{References}

[1] E. DeRitter, "Vitamins in pharmaceutical formulations," Journal of Pharmaceutical Sciences, vol. 71, no. 10, pp. 1073-1096, 1982.

[2] British Pharmacopoeia, Monograph on Riboflavin, Her Majesty's Stationary Office, London, UK, 2013.

[3] M. J. O’Neil, The Merck Index, Merck \& Co., Rahway, NJ, USA, 15th edition, 2013.

[4] G. R. Penzer and G. K. Radda, "[152] Photochemistry of flavins," Methods in Enzymology: Part B, vol. 18, pp. 479-495, 1971.

[5] P. S. Song, "Chemistry of flavins in their excited states," in Flavins and Flavoprotein, H. Kamin, Ed., pp. 37-31, University Park Press, Baltimore, Md, USA, 1971.

[6] M. Schuman Jorns, G. Schoellnhammer, and P. Hemmerich, "Intramolecular addition of the riboflavin side chain. Anion catalyzed neutral photochemistry," European Journal of Biochemistry, vol. 57, no. 1, pp. 35-48, 1975.

[7] P. F. Heelis, "The photophysical and photochemical properties of flavins (isoalloxazines)," Chemical Society Reviews, vol. 11, no. 1, pp. 15-39, 1982.

[8] P. F. Heelis, "The photochemistry of flavins," in Chemistry and Biochemistry of Flavoenzymes, F. Muller, Ed., pp. 171-193, CRC Press, Boca Raton, Fla, USA, 1993.

[9] G. Tollin, "Use of flavin photochemistry to probe intraprotein and interprotein electron transfer mechanisms," Journal of Bioenergetics and Biomembranes, vol. 27, no. 3, pp. 303-309, 1995.

[10] I. Ahmad and F. H. M. Vaid, "Photochemistry of flavins in aqueous and organic solvents," in Flavin Photochemistry and Photobiology, E. Silva and A. M. Edwards, Eds., chapter 2, The Royal Society of Chemistry, Cambridge, UK, 2006.

[11] O. Warburg and W. Christian, "The yellow enzyme and its functions," Biochemische Zeitschrift, vol. 266, pp. 377-411, 1936.

[12] E. C. Smith and D. E. Metzler, "The photochemical degradation of riboflavin," Journal of the American Chemical Society, vol. 85, no. 20, pp. 3285-3288, 1963.
[13] G. E. Treadwell, W. L. Cairns, and D. E. Metzler, "Photochemical degradation of flavins. V. Chromatographic studies of the products of photolysis of riboflavin," Journal of Chromatography A, vol. 35, no. 3, pp. 376-388, 1968.

[14] I. Ahmad and H. D. C. Rapson, "Multicomponent spectrophotometric assay of riboflavine and photoproducts," Journal of Pharmaceutical and Biomedical Analysis, vol. 8, no. 3, pp. 217223, 1990.

[15] I. Ahmad, Q. Fasihullah, and F. H. M. Vaid, "A study of simultaneous photolysis and photoaddition reactions of riboflavin in aqueous solution," Journal of Photochemistry and Photobiology B: Biology, vol. 75, no. 1-2, pp. 13-20, 2004.

[16] I. Ahmad, Q. Fasihullah, A. Noor, I. A. Ansari, and Q. N. M. Ali, "Photolysis of riboflavin in aqueous solution: a kinetic study," International Journal of Pharmaceutics, vol. 280, no. 1-2, pp. 199208, 2004.

[17] M. A. Sheraz, S. H. Kazi, S. Ahmed, Z. Anwar, and I. Ahmad, "Photo, thermal and chemical degradation of riboflavin," Beilstein Journal of Organic Chemistry, vol. 10, pp. 1999-2012, 2014.

[18] I. Ahmad, T. Mirza, K. Iqbal, S. Ahmed, M. A. Sheraz, and F. H. M. Vaid, "Effect of $\mathrm{pH}$, buffer, and viscosity on the photolysis of formylmethylflavin: a kinetic study," Australian Journal of Chemistry, vol. 66, no. 5, pp. 579-585, 2013.

[19] W. M. Moore, J. T. Spence, F. A. Raymond, and S. D. Colson, "The photochemistry of riboflavin. I. The hydrogen transfer process in the anaerobic photobleaching of flavins," Journal of the American Chemical Society, vol. 85, no. 21, pp. 3367-3372, 1963.

[20] B. Holmstorm, "The mechanism of the photoreduction of riboflavin," Arkiv för Kemi, vol. 22, no. 8, pp. 329-346, 1964.

[21] G. K. Radda and M. Calvin, "Chemical and photochemical reductions of flavin nucleotides and analogs," Biochemistry, vol. 3, no. 3, pp. 384-393, 1964.

[22] J. Koaiol, "Studies on flavins in organic solvents-II. Photodecomposition of riboflavin in the presence of oxygen," Photochemistry and Photobiology, vol. 5, no. 1, pp. 55-62, 1966.

[23] W. E. Kurtin, M. A. Latino, and P. S. Song, "A study of photochemistry of flavins in pyridine and with a donor," Photochemistry and Photobiology, vol. 6, no. 4, pp. 247-259, 1967.

[24] W. W. Moore and R. C. Ireton, "The photochemistry of riboflavin $-\mathrm{V}$. The photodegradation of isoalloxazines in alcoholic solvents," Photochemistry and Photobiology, vol. 25, no. 4, pp. 347-356, 1977.

[25] P. F. Heelis, B. J. Parson, and G. O. Phillips, “The pH dependence of the reactions of flavin triplet states with amino acids. A laser flash photolysis study," Biochimca et Biophysica Acta, vol. 587, no. 3, pp. 455-462, 1979.

[26] B. J. Fritz, S. Kasai, and K. Matsui, "Photochemical properties of flavin derivatives," Photochemistry and Photobiology, vol. 45, no. 1, pp. 113-117, 1987.

[27] M. A. Sheraz, S. H. Kazi, S. Ahmed, K. Qadeer, M. F. Khan, and I. Ahmad, "Multicomponent spectrometric analysis of riboflavin and photoproducts and their kinetic applications," Central European Journal of Chemistry, vol. 12, no. 6, pp. 635642, 2014.

[28] I. Ahmad, H. D. C. Rapson, P. P. Heelis, and G. O. Phillips, "Alkaline hydrolysis of 7,8-dimethyl-10-(formylmethyl)isoalloxazine. A kinetic study," Journal of Organic Chemistry, vol. 45, no. 4, pp. 731-733, 1980.

[29] X.-Q. Guo, J.-G. Xu, Y.-Z. Wu, Y.-B. Zhao, X.-Z. Huang, and G.-Z. Chen, "Determination of thiamine (vitamin $B_{1}$ ) by in 
situ sensitized photochemical spectrofluorimetry," Analytica Chimica Acta, vol. 276, no. 1, pp. 151-160, 1993.

[30] A. Wasielczuk, M. Catalá Icardo, J. V. García Mateo, and J. Martínez Calatayud, "Flow-injection chemiluminescent determination of thiamine in pharmaceutical samples by on-line photodegradation," Analytical Letters, vol. 37, no. 15, pp. 32053218, 2004.

[31] H. H. Fall and H. G. Petering, "Metabolite inhibitors. I. 6,7-dimethyl-9-formylmethylisoalloxazine, 6,7-dimethyl-9-(2' hydroxyethyl)-isoalloxazine and derivatives," Journal of the American Chemical Society, vol. 78, no. 2, pp. 377-380, 1956.

[32] C. G. Hatchard and C. A. Parker, "A new sensitive chemical actinometer. II. Potassium ferrioxalate as a standard chemical actinometer," Proceeding of Royal Society of London: Series A, Mathematical and Physical Sciences, vol. 235, no. 1203, pp. 518536, 1956.

[33] I. Ahmad, Z. Anwar, K. Iqbal et al., "Effect of acetate and carbonate buffers on the photolysis of riboflavin in aqueous solution: a kinetic study," AAPS PharmSciTech, vol. 15, no. 3, pp. 550-559, 2014.

[34] C. H. Suelter and D. E. Metzler, "The oxidation of a reduced pyridine nucleotide analog by flavins," Biochimica et Biophysica Acta, vol. 44, pp. 23-33, 1960.

[35] P. S. Song and D. E. Metzler, "Photochemical degradation of flavins. IV. Studies of the anaerobic photolysis of riboflavin," Photochemistry and Photobiology, vol. 6, no. 10, pp. 691-709, 1967.

[36] US Pharmacopeial Convention, United States Pharmacopoeia 29, United States Pharmacopoeial Convention, Rockville, Md, USA, 2006.

[37] D. A. Wadke and D. E. Guttman, "Hydrolytic behavior of isoalloxazine related to riboflavin I. Identification of an intermediate products in the base-catalyzed degradation of 9methylisoalloxazine," Journal of Pharmaceutical Sciences, vol. 55, no. 10, pp. 1088-1092, 1966.

[38] D. A. Wadke and D. E. Guttman, "Hydrolytic behavior of isoalloxazine related to riboflavin II. Kinetics of degradation of 9-methylisoalloxazine in alkaline media," Journal of Pharmaceutical Sciences, vol. 55, no. 12, pp. 1363-1368, 1966.

[39] D. E. Guttman and T. E. Platek, "Hydrolytic behavior of isoalloxazine related to riboflavin. III. Covalent hydration of 1,2dihydro-1-methyl-2-oxoquinoxaline-3-carboxyureide," Journal of Pharmaceutical Sciences, vol. 56, no. 11, pp. 1423-1427, 1967.

[40] J. Koziol, "Studies on flavins in organic solvents-I. Spectral characteristics of riboflavin, riboflavin tetrabutyrate and lumichrome," Photochemistry and Photobiology, vol. 5, no. 1, pp. 41-54, 1966. 

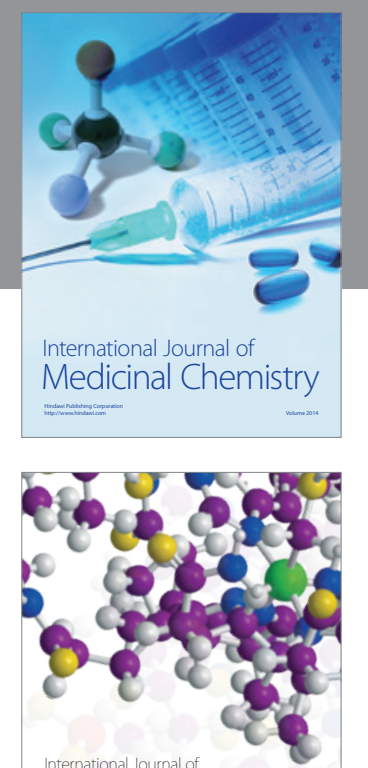

\section{Carbohydrate} Chemistry

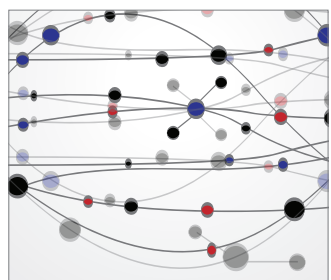

The Scientific World Journal

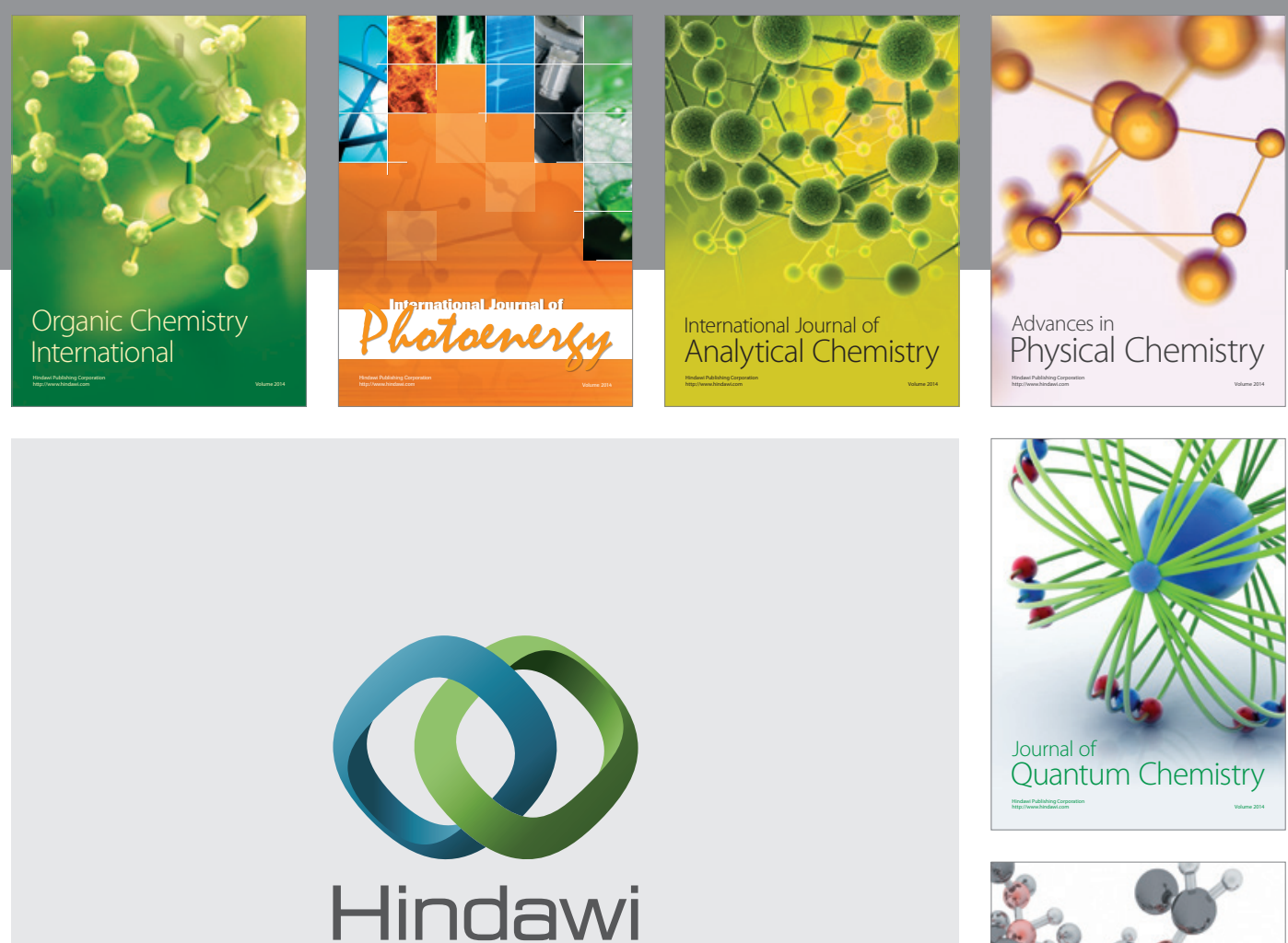

Submit your manuscripts at

http://www.hindawi.com

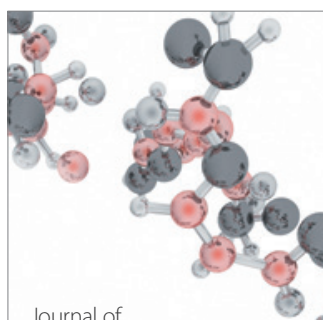

Analytical Methods

in Chemistry

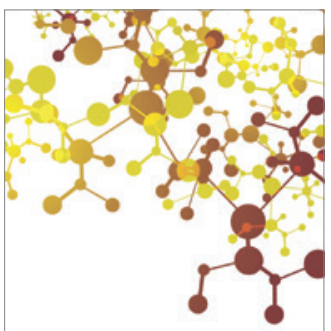

Journal of

Applied Chemistry

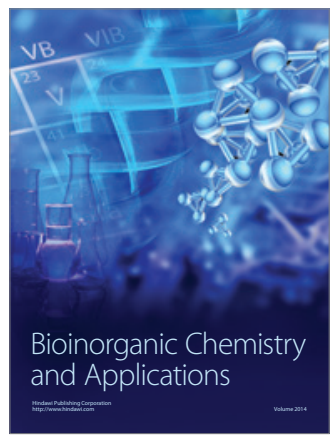

Inorganic Chemistry
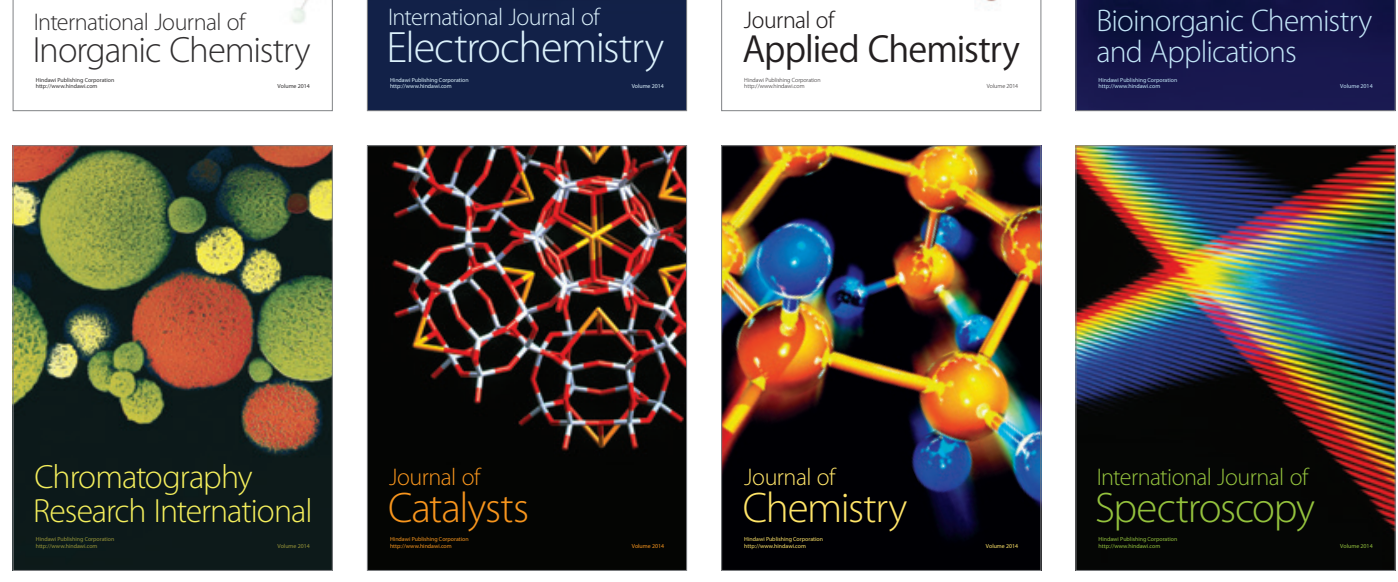